\title{
In situ neutron diffraction analyses of temperature and stresses during friction stir processing of Mg-3Al-1Zn magnesium alloy
}

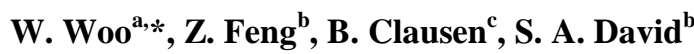 \\ ${ }^{a}$ Neutron Science Division, Korea Atomic Energy Research Institute, Daejeon, 34057, South Korea \\ ${ }^{b}$ Materials Science and Technology Division, Oak Ridge National Laboratory, Oak Ridge, TN 37831, USA \\ ${ }^{c}$ Materials Science in Radiation and Dynamics Extremes, Los Alamos National Laboratory, Los Alamos, NM
}

87545, USA

The evolution of temperature and thermal stresses were examined during friction stir processing of a magnesium alloy using in situ neutron diffraction. Measured total lattice strains were de-convoluted into the thermal and stress components. It shows the maximum temperature of $464{ }^{\circ} \mathrm{C}$ and compressive stress distributions up to -52 MPa underneath the tool via the thermo-mechanical deformation in terms of the Zener-Hollomon parameter of $4.51 \times 10^{10} \mathrm{~s}^{-1}$.

Keywords: Friction stir processing; Magnesium alloy; Neutron diffraction; Temperature; Stress

\section{Introduction}

Although magnesium alloys attract significant attention in the transportation industry as a lightweight structural material, the poor workability restricts the range of applications [1]. Friction-stir processing (FSP) is a newly developed microstructural modification process utilizing a rotating tool consisting of a threaded pin and tool shoulder to apply severe plastic deformation and frictional heating into the materials [2]. It has been known that the grainrefinement via dynamic recrystallization of FSP can improve the formability of $\mathrm{Mg}$ alloys $[3,4]$. Extensive studies show that the temperature, flow stress, and strain rate of the Mg FSP

$$
-1 \text { - }
$$


are the key parameters for the proper microstructure and enhanced mechanical properties [5$10]$.

In specific, the Zener-Hollomon parameter $(Z)$, which is the temperature compensated strain rate, has been suggested as a major factor to control the grain size and hardness of $\mathrm{Mg}$ FSP [8-10]. Since the $Z$ parameter is defined as $\varepsilon^{\bullet} \exp (Q / R T)$ in terms of strain rate $(\dot{\varepsilon})$, temperature $(\mathrm{T})$, activation energy $(Q)$, and gas constant $(R)$, it is critical to determine the precise temperature during FSP. A number of theoretical, computational studies and experimental approaches based on the thermocouple-insert method have been performed [712]. However, non-destructive measurements of the temperature evolution underneath the tool are hardly reported due to the severe plastic deformation of the fast rotating tool during FSP. Thus, this work utilizes a novel approach of the time-resolved neutron diffraction measurement method for the in situ real-time study of the transient materials behavior using the drastically improved neutron temporal resolution [13].

The purpose of this paper is to determine the transient temperature and stress distributions ahead, underneath, and behind the tool during Mg FSP. In situ neutron diffraction measurements quantitatively provide processing parameters influencing the microstructure and mechanical property of the Mg FSP. The results expand this methodology to the plastic anisotropic hcp Mg alloy revealing inhomogeneous properties underneath the FSP tool.

\section{Experimental details}

As-received commercial AZ31B Mg alloy (3.0 Al, 1.0 Zn, 0.2 Mn, and balance $\mathrm{Mg}$ in wt.\%) plates in the soft-annealed condition were used with the typical hot-rolling texture. The averaged initial grain size was about $56 \mu \mathrm{m}$ as shown in Fig. 1. The dimension of the $\mathrm{Mg}$ plate specimen was $965-\mathrm{mm}$ long, 178-mm wide, and 6.35-mm thick. The diameter of the threaded tool pin and shoulder in the FSP machine was 6.35 and $25.4 \mathrm{~mm}$, respectively. The 
tool rotated at the speed of $300 \mathrm{rpm}$ and the traveling speed of $28 \mathrm{~mm} / \mathrm{min}$. The tool was applied the forging force of $8500 \mathrm{~N}$ along the $z$ direction. Approximately $25 \mathrm{~mm}$ width and $700 \mathrm{~mm}$ long deformation zone was created with the average grain size of $13.9 \mu \mathrm{m}$ after FSP.

In situ neutron diffraction experiments were performed using the Spectrometer for MAterials Research at Temperature and Stress (SMARTS) in the Los Alamos Neutron Science Center, Fig. 1. The neutron beam was impinged on "before" (-15 mm), "during" (-6, 6, $10 \mathrm{~mm})$, and "after" $(15,20,50 \mathrm{~mm})$ FSP locations. Underneath the tool a total of six positions were additionally measured with $6 \mathrm{~mm}$ intervals. The neutron beam volume was $2(x) \times 3(y) \times 2(z) \mathrm{mm}^{3}$ focused on the mid-thickness of the plate. The d-spacing (interplanar spacing $)$ along the longitudinal $\left(\mathrm{Q}_{\mathrm{LD}} / / x\right)$ and normal $\left(\mathrm{Q}_{\mathrm{ND}} / / z\right)$ directions of the plate were measured simultaneously. In order to determine the d-spacing along the $y$ direction $\left(\mathrm{Q}_{\mathrm{TD}} / / \mathrm{y}\right)$, it needs to rotate the whole machine with the sample 90 degrees relative to the neutron detector (a vertical set up). Note that we utilized the time-resolved neutron diffraction measurement method based on the quasi-steady state phenomenon under the Eulerian coordinate [13]. Thus, the neutron beam is fixed at a location as the specimen moves along the $x$ direction.

\section{Diffraction peak analysis methods}

Figure 2(a) shows the diffraction peaks of the longitudinal component obtained at different distance between the beam and the tool center. It was fitted using Rietveld peak refinement by comparing the measured peak and calculated crystallographic profile based on the space group (P63/mmc) of hcp Mg. It determined the d-spacings $(d)$, which show the largest one at the \pm 6 -mm location due to the highest thermal expansion compared to the "stress-free" d-spacing $\left(d_{o}\right)$. Moreover, it shows clearly the intensity changes between the 
prismatic (10-10) and basal (0002) planes. It means the destruction and evolution of the preferred orientation of grains during Mg FSP [4].

The $d$ was converted to the lattice strain $(\varepsilon)$ by the equation: $\varepsilon=\left(d-d_{o}\right) / d_{o}$. In order to represent the average plastic anisotropic response of the hcp $\mathrm{Mg}$ alloy the $\varepsilon$ was calculated by $\varepsilon_{i}=\left(2 \varepsilon_{i}^{a-a x i s}+\varepsilon_{i}^{c-a x i s}\right) / 3, \mathrm{i}=(x, y, z)[14]$. Figure 2(b) shows the total lattice strains as a function of distance from the tool center. The three strain components $\left(\varepsilon_{x}, \varepsilon_{y}\right.$, and $\left.\varepsilon_{z}\right)$ were measured with their scattering vectors $(Q)$ parallel to the three orthogonal directions $(x, y$, and z) of the plate, respectively. Repeat measurements were performed at the -15 and $20 \mathrm{~mm}$ positions and it shows highly repeatable results in Fig. 2(b).

The total lattice strains $(\varepsilon)$ include both thermal strains $\left(\varepsilon^{\text {th }}\right)$ and elastic strains $\left(\varepsilon^{e}\right)$ by convoluting the thermal expansion and constraints by surrounding cold materials during FSP. In order to separate the temperature $(T)$ and stresses $\left(\sigma_{x}, \sigma_{y}\right)$, we followed the data analysis method [13]. The Hooke's law relates the two normal stress components $\left(\sigma_{x}, \sigma_{y}\right)$ to the three normal elastic strain components $\left(\varepsilon_{x}^{e}, \varepsilon_{y}^{e}, \varepsilon_{z}^{e}\right)$ and a stress component along $z$ direction $\left(\sigma_{z}\right)$ :

$$
\sigma_{i}=\frac{E}{1+v}\left(\varepsilon_{i}^{e}-\varepsilon_{z}^{e}\right)+\sigma_{z}=\frac{E}{1+v}\left(\varepsilon_{i}-\varepsilon_{z}\right)+\sigma_{z} ; \quad i=x, y
$$

where $E$ and $v$ are the elastic modulus and Poisson's ratio, respectively. For the thermally isotropic materials $\left(\varepsilon_{x}^{t h}=\varepsilon_{y}^{t h}=\varepsilon_{z}^{t h}\right)$, it then drives; $\varepsilon_{i}^{e}-\varepsilon_{z}^{e}=\varepsilon_{i}-\varepsilon_{z}, i=(x, y)$ as shown in Eq. (1). The temperature $(T)$ was calculated from the thermal strains $\left(\varepsilon^{\text {th }}\right)$ divided by thermal expansion coefficient $(\alpha)$ :

$$
T=T_{O}+\frac{1}{\alpha}\left[\frac{v}{1+v}\left(\varepsilon_{x}+\varepsilon_{y}\right)+\frac{1-v}{1+v} \varepsilon_{z}+\frac{(2 v-1)}{E} \sigma_{z}\right]
$$

Since the $E$ and $\alpha$ is temperature dependent, the $T$ was obtained by the three iterations. The parameters were initially $22 \mathrm{GPa}, 34 \times 10^{-6}{ }^{\circ} \mathrm{C}^{-1}$ at $450{ }^{\circ} \mathrm{C}$, respectively [15]. The constant Poisson's ratio $(v, 0.35)$ was used due to the weak temperature dependence. For the thin plate, 
it is assumed the plane stress $\left(\sigma_{z}=0\right)$ outside the rotating tool and the $\sigma_{z}$ of -17 MP underneath the tool calculated the forging force divided by the area of the tool shoulder.

\section{Results and discussion}

Figure 3(a) shows the temperature profile as a function of distance from the tool center. The temperature is about $390{ }^{\circ} \mathrm{C}$ at the $-15 \mathrm{~mm}$ position before FSP and increases underneath the tool reaching the maximum $\left(464{ }^{\circ} \mathrm{C}\right)$ at the $6 \mathrm{~mm}$ position. Then it exponentially decreases to $297{ }^{\circ} \mathrm{C}$ at $50 \mathrm{~mm}$ position. The maximum temperature is highly comparable to the calculation $\left(467{ }^{\circ} \mathrm{C}\right)$ obtained by the Arbegast's equation $[8] ; T / T_{m}=K\left[W^{2} /\left(V \cdot 10^{4}\right)\right]^{\alpha}$, using the rotation rate $(W, 300 \mathrm{rpm})$, welding speed $(V, 28 \mathrm{~mm} / \mathrm{min})$, melting temperature $\left(T_{m}\right.$, $\left.610{ }^{\circ} \mathrm{C}\right)$, and suggested the constants $(K=0.8052, \alpha=0.0442)$. The strain rate $(\dot{\varepsilon})$ was estimated as $12.1 \mathrm{~s}^{-1}$ using the torsion type deformation; $R_{m} \bullet 2 \pi r_{e} / L_{e}$, where $R_{m}$ is half of the rotation speed $\left(2.5 \mathrm{~s}^{-1}\right), r_{e} / L_{e}$ is the ratio $(0.77)$ of the average radius $(5.6 \mathrm{~mm})$ to depth $(4.3$ $\mathrm{mm}$ ) of the recrystallization zone [5]. Thus, it leads the $Z$ of $4.51 \times 10^{10} \mathrm{~s}^{-1}$ by the equation; $\varepsilon^{\bullet} \exp (Q / R T)$ where $Q$ is the activation energy (135 kJ/mol), $R$ is the gas constant [8].

The $Z$ parameter can be correlated to the grain structure via the Chang's model [5]; In $\left(D_{\text {rec }}\right)=9-0.27 \ln Z$ and Watanabe's model [16]; $D_{\text {red }} / D_{\text {ini }}=10^{3} Z^{-1 / 3}$, where $D_{\text {rec }}$ and $D_{\text {ini }}$ is the grain size of the recrystallization and initial state, respectively. Thus, the $Z$ parameter projects the $D_{\text {rec }}$ of $10.8 \mu \mathrm{m}$ and $D_{\text {rec }} / D_{\text {ini }}$ of 0.28 . It is in good agreement with $13.9 \mu \mathrm{m}$ and $0.25(13.9$ $\mu \mathrm{m} / 56 \mu \mathrm{m}$ ), which were measured from the microstructure in Fig. 1. Besides, the measured grain size $\left(D_{\text {meas }}\right)$ is within the range when applied to the recent relationship between $D_{\text {rec }}$ and $\mathrm{Z}$ parameter suggested by $\mathrm{Yu}$ [9] and Ammouri et al. [10] as summarized in Table 1.

Figure 3(b) shows the thermal stress distribution during FSP. Both the longitudinal $\left(\sigma_{x}\right)$ and transverse $\left(\sigma_{y}\right)$ stresses show compression up to -46 $\mathrm{MPa}$ underneath the tool due to the constraints of the cold materials. It is plausible when comparing the yield strength of $\sim 60$ MPa at $400{ }^{\circ} \mathrm{C}$ under the strain rate of $1 \mathrm{~s}^{-1}$ of AZ31B Mg alloy [7]. The similarity between $\sigma_{x}$ 
and $\sigma_{y}$ can be attributed to the slow movement of the heat source onto the nearly thermally isotropic $\mathrm{Mg}$ alloy [15]. Finally, the compression becomes tension behind the tool and remains as the residual stress on cooling. The magnitude of $\sim 10 \mathrm{MPa}$ is similar to the result of the residual stress measurement of Mg FSP in literature [17].

Figure 3(c) shows the temperature and stress distributions underneath the tool shoulder. In the perspective of temperature and stress differences underneath the tool, it is likely that the region could be divided by two (Zone I and Zone II) marked in Fig. 3(c). The temperature is relatively lower and the stresses are more compressive in Zone I compared to those of Zone II. For example, the temperature is lower up to $26^{\circ} \mathrm{C}$ and the absolute magnitudes of the stress are mostly higher in Zone I. It can be attributed to the relatively cold, new plasticized materials floating from the front toward the region behind the tool pin sketched as a material flow in Fig. 3(c) [11,12]. Albakri et al., simulated plasticized material streamlines starting from the forehead advancing side, swept along the tool pin surface, and flowing toward the retreating side behind in AZ31 Mg FSP [12]. Thus, higher temperature and lower flow stresses create the compliant Zone II during Mg FSP. Although the relatively low weld pitch (the tool advance per rotation) of $0.09 \mathrm{~mm} /$ rotation condition [4-10], it shows inhomogeneous distributions of the temperature and stresses underneath the tool during Mg FSP.

\section{Conclusion}

Transient temperature and thermal stress distributions were investigated during FSP of AZ31B Mg using in-situ neutron diffraction. The precise analysis of temperature $\left(464{ }^{\circ} \mathrm{C}\right)$ provides the Zener-Hollomon parameter of $4.51 \times 10^{10} \mathrm{~s}^{-1}$ and the grain size in the range of 12.2-15.2 $\mu \mathrm{m}$ via FSP. In situ neutron experiments revealed non-uniform temperature and compressive stress distributions underneath the tool during Mg FSP. 


\section{Acknowledgements}

This work was supported by the Department of Energy's Office of Basic Energy under contract DE-AC52-06NA25396 and National Research Foundation of Korea grant funded by the Korean government (No. NRF-2012M2A2A6004262).

\section{References}

[1] H. Friedrich, S. Schumann, J. Mater. Process. Tech. 117 (2001) 276-281.

[2] R.S. Mishira, Z.Y. Ma, Mater. Sci. Eng. R, 50 (2005) 1-78.

[3] C.I. Chang, X. Du, J. Huang, Scripta Mater. 57 (2007) 209-212.

[4] Z. Yu, H. Choo, Z.L. Feng, S.C. Vogel, Scripta Mater. 63 (2010) 1112-1115.

[5] C.I. Chang, C.J. Lee, J.C. Huang, Scripta Mater. 51 (2004) 509-514.

[6] N. Afrin, D.L. Chen, X. Cao, M. Janazi, Scripta Mater. 57 (2007) 1004-1007.

[7] J. Liu, Z. Cui, C.Li, Comp. Mater. Sci. 41 (2008) 375-382.

[8] L. Commin, M. Dumont, J.-E. Masse, L. Barrallier, Acta Mater. 57 (2009) 326-334.

[9] Z. Yu, H. Choo, Scripta Mater. 64 (2011) 434-437.

[10] A.H. Ammouri, G. Kridli, G. Ayoub, R.F. Hamade, J. Mater. Proc. Tech. 222 (2015) 301-306.

[11] A. Arora, Z. Zhang, A. De, T. DebRoy, Scripa Mater. 61 (2009) 863-866.

[12] A.N. Albakri, B. Mansoor, H. Nassar, M.K. Khraisheh, J. Mater. Proc. Tech. 213 (2013) 279-290.

[13] W. Woo, Z. Feng, X.-L. Wang, D.W. Brown, B. Clausen, K. An, H. Choo, C.R. Hubbard, S.A. David, Sci. Tech. Welding Joining 12 (2007) 298-303.

[14] M.R. Daymond, M.A.M. Bourke, R.B. Von Dreele, J. Appl. Phys. 85 (1999) 739-747.

[15] R.S. Busk, Magnesium Products Design, Marcel Dekker INC. NewYork, 1996.

[16] H. Watanabe, H. Tsutsui, T. Mukai, H. Ishikawa, Y. Okanda, M. Kohzu, K. Higashi, Mater. Trans. 42 (2001) 1200-1205.

[17] W. Woo, H. Choo, M.B. Prime, Z. Feng, B. Clausen, Acta Mater. 56 (2008) 1701-1711.

Fig. 1. Microstructure of the base metal (BM) and friction stir processing (FSP) of AZ31B $\mathrm{Mg}$ alloy. Experimental set up of in situ neutron diffraction.

Fig. 2. (a) Diffraction peak profiles during FSP, (b) total lattice strains $\left(\varepsilon_{x}, \varepsilon_{y}\right.$, and $\left.\varepsilon_{z}\right)$ as a function of distance from the tool center.

Fig. 3. Distributions of (a) temperature, (b) thermal stresses $\left(\sigma_{x}, \sigma_{y}\right)$, and (c) both underneath tool during Mg FSP.

Table. 1. Rotational rate (W), speed (V), temperature (T), strain rate ( $\dot{\varepsilon})$, Zener-Hollomon parameter (Z), and grain size (D) of AZ31B Mg FSP. 


\section{Figure 1}
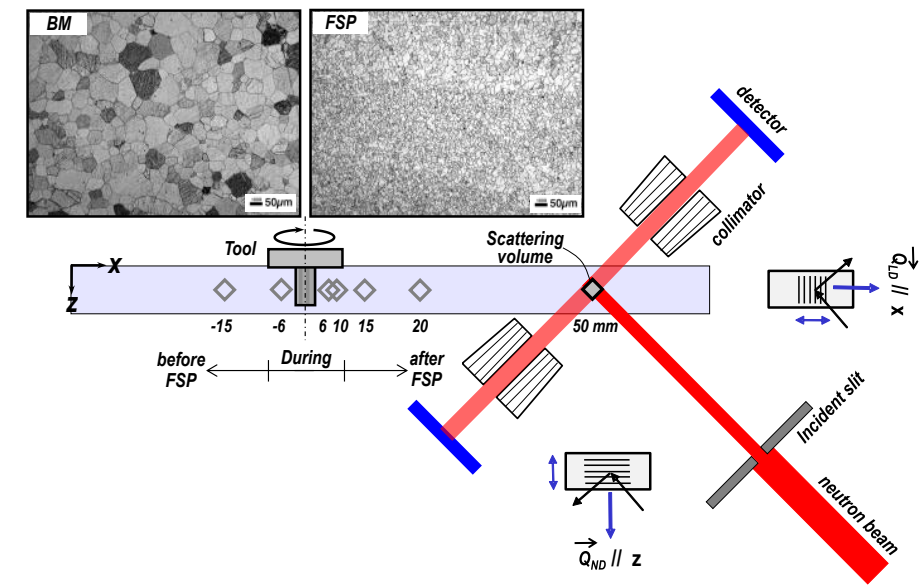

\section{Figure 2}
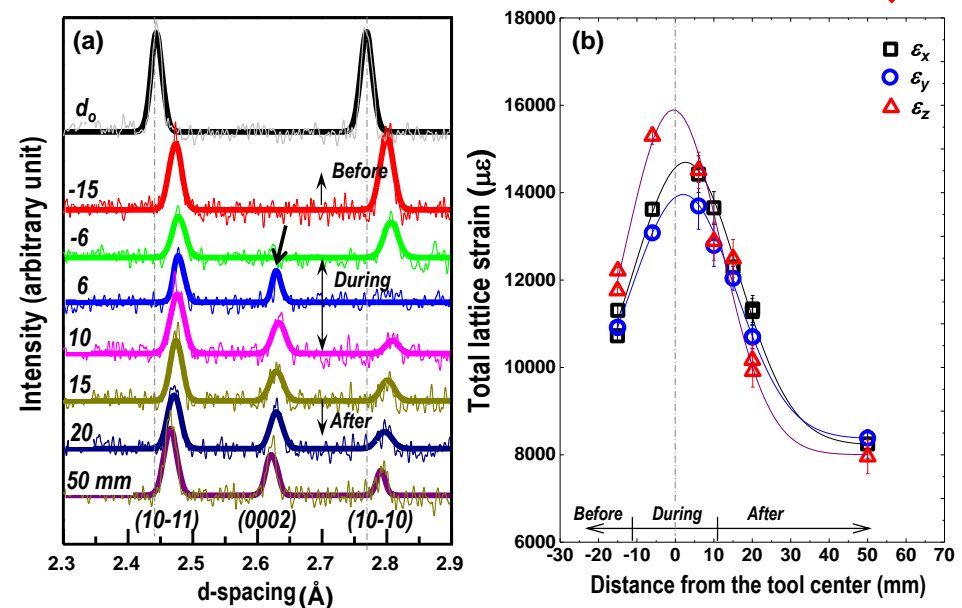

\section{Figure 3}
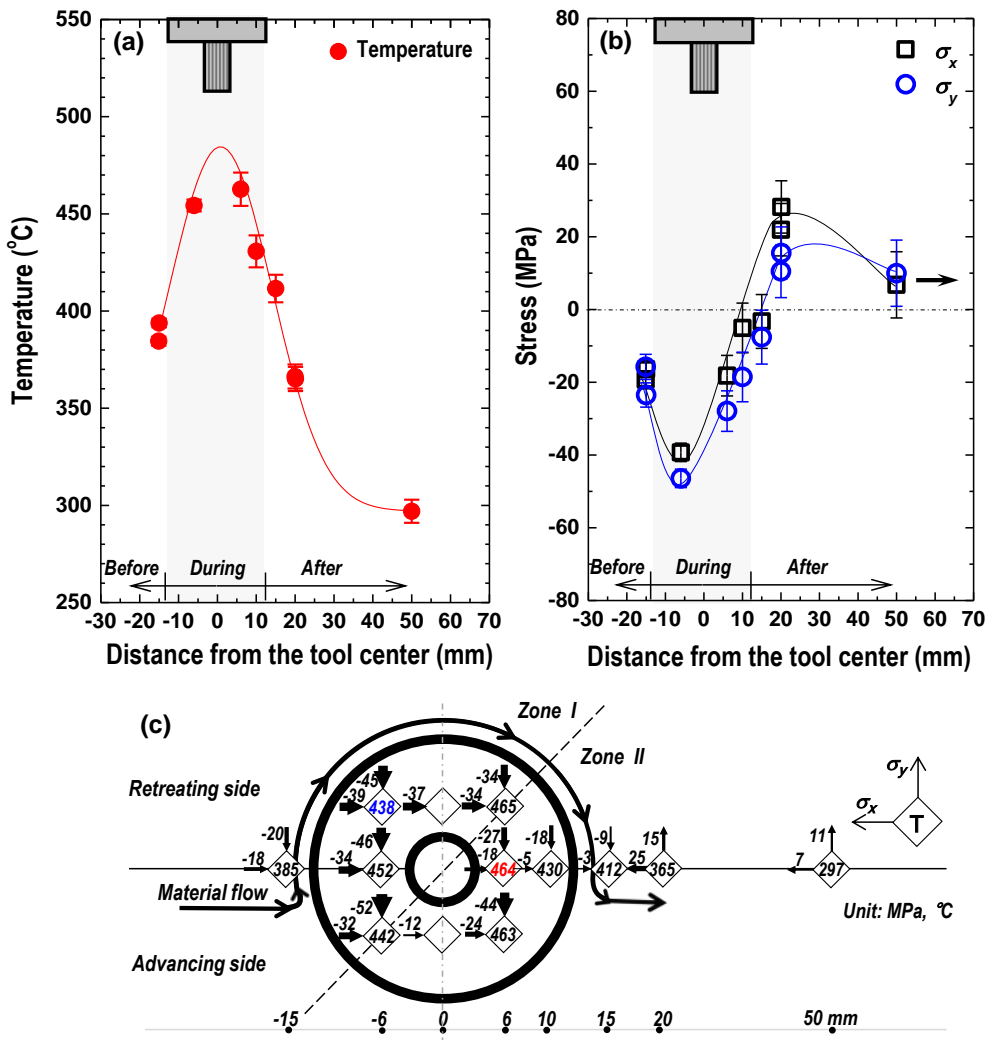

Table 1

\begin{tabular}{cccccccc}
\hline$W(\mathrm{rpm})$ & $V(\mathrm{~mm} / \mathrm{min})$ & $T_{\text {cal }}\left({ }^{\circ} \mathrm{C}\right)$ & $T_{\text {meas }}\left({ }^{\circ} \mathrm{C}\right)$ & $\dot{\varepsilon}\left(\mathrm{s}^{-1}\right)$ & $Z\left(\mathrm{~s}^{-1}\right)$ & $D_{\text {cal }}(\mu \mathrm{m})$ & $D_{\text {meas }}(\mu \mathrm{m})$ \\
\hline 300 & 28 & 467 & 464 & 12.1 & $4.51 \times 10^{10}$ & $9.2-23.2$ & $12.2-15.2$
\end{tabular}




\section{Graphical abstract}

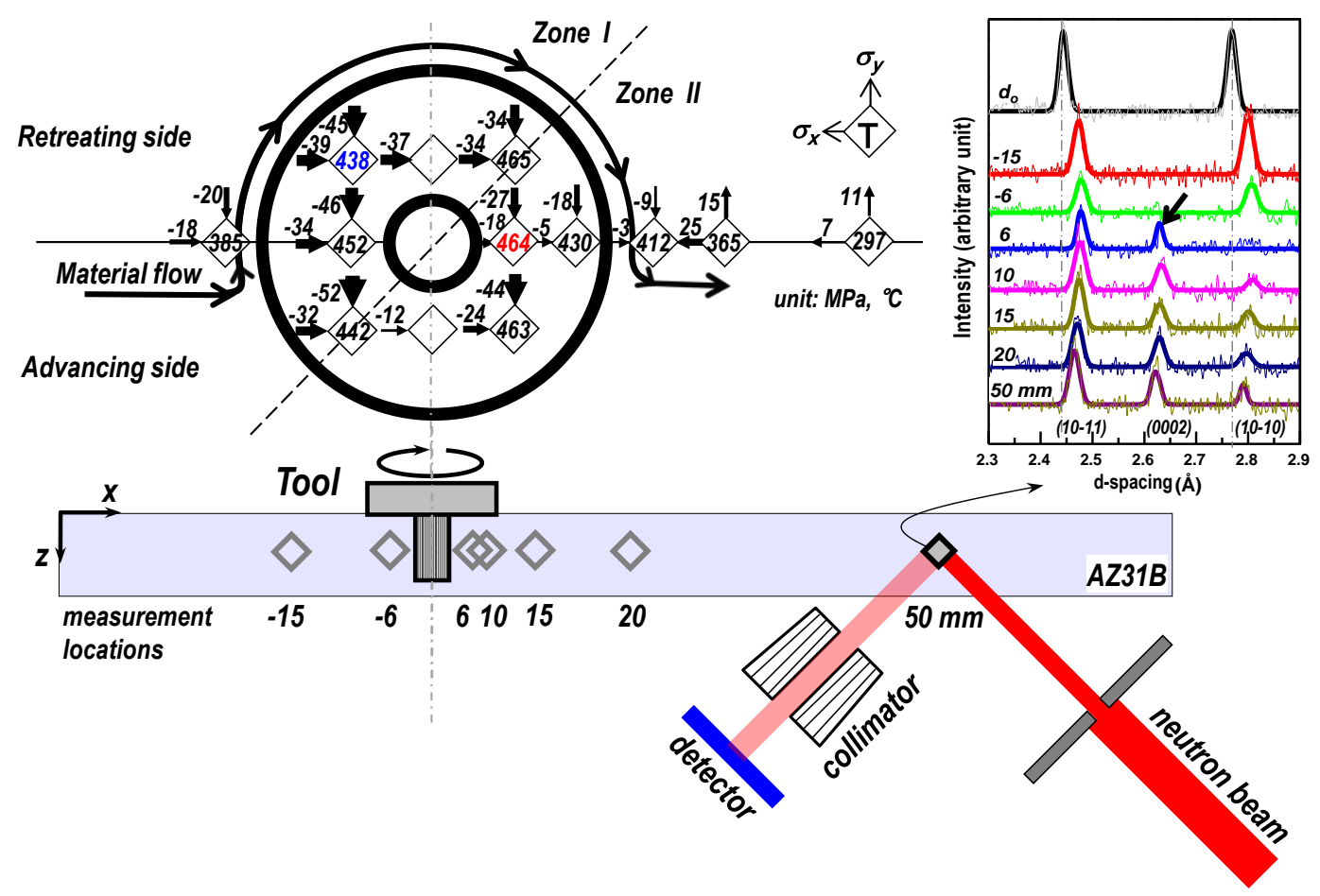

